\title{
Systemic Reform in Practice: Merck Institute for Science Education
}

Consortium for Policy Research in Education

Follow this and additional works at: https://repository.upenn.edu/cpre_researchreports

Part of the Adult and Continuing Education and Teaching Commons, Curriculum and Instruction Commons, Educational Administration and Supervision Commons, Higher Education Commons, and the Science and Mathematics Education Commons

\section{Recommended Citation}

Consortium for Policy Research in Education. (2003). Systemic Reform in Practice: Merck Institute for Science Education. CPRE Research Reports.

Retrieved from https://repository.upenn.edu/cpre_researchreports/33

View on the CPRE website.

This paper is posted at ScholarlyCommons. https://repository.upenn.edu/cpre_researchreports/33

For more information, please contact repository@pobox.upenn.edu. 


\title{
Systemic Reform in Practice: Merck Institute for Science Education
}

\author{
Abstract \\ MISE began partnering with four school districts - three in New Jersey and one in Pennsylvania - in \\ 1993. The success that the partners have had in improving instructional practice in science is anchored in \\ the belief that to make lasting improvement in teaching and, consequently in learning, one must work \\ systemically on multiple domains of the district and school culture at the same time. MISE invited four \\ school districts to come together to build a professional community in science, a community which \\ valued teacher expertise and invested in the continued professional learning for teachers, a community \\ that worked together to improve teaching and learning in science. MISE worked with its partners to create \\ their own professional communities, to build their capacity to support the continuous improvement of \\ teaching, and to align their policies and resources with their shared vision of good practice. \\ Disciplines \\ Adult and Continuing Education and Teaching | Curriculum and Instruction | Educational Administration \\ and Supervision | Higher Education | Science and Mathematics Education | Teacher Education and \\ Professional Development \\ Comments \\ View on the CPRE website.
}


Penn GSE

GRE

University of Pennsylvania

3440 Market Street, Suite 560

Telephone 215-573-0700

Fax 215-573-7914

www.cpre.org

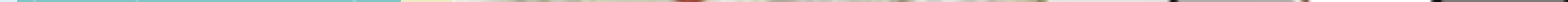




\section{About MISE}

Merck \& Co., Inc. has an extensive and proud history of supporting public education. Long before school-business partnerships became popular, Merck was contributing grants, gifts, and the time and talent of its employees to the improvement of science education in the local public schools. These efforts, although generous, were seldom coordinated or focused to maximize their impact, and they seldom affected all of the students in participating schools. Merck's leaders were not satisfied with the results they were obtaining. In I990, they committed themselves to the goal of making the United States the first in the world in science and mathematics education, and they knew from their own experience that a larger investmen and a more disciplined effort would be required to achieve such an ambitious goal. They also knew that they would have to make a long-term commitment.

In 1993, Merck made this commitment, adopting a more activist, focused corporate strategy by creating the Merck Institute for Science Education (MISE). Backed by a IO-year commitment from the corporation, the goal of MISE has been to raise student interest, participation, and performance in science so that all children could meet

challenging national and state standards. MISE initiated its work by forming partnerships with four public school districts-Linden, Rahway, and Readington Township in New Jersey, and North Penn in Pennsylvania-where Merck had major facilities. Merck had a history of assisting the schools in these communities, and their public schools welcomed the idea of partnering with the new Institute.

To learn more about MISE, visit www.mise.org.

\section{About GPRE}

The Consortium for Policy Research in Education (CPRE) unites five of the nation's top research institutions in an exciting venture to improve student learning through research on policy, finance, school reform, and school governance. The members of CPRE are the University of Pennsylvania, Harvard University, Stanford University. the University of Michigan, and the University of Wisconsin-Madison.

CPRE is currently examining how alternative approaches to reform-such as instructional approaches to reform-such as instructional improvement, new accountability poicicies, teacher compensaches-address issues of coherence, incentives, and capacity.

To learn more about CPRE, visit www.cpre.org or call (215) 573-0700. and then press 0 for assistance.

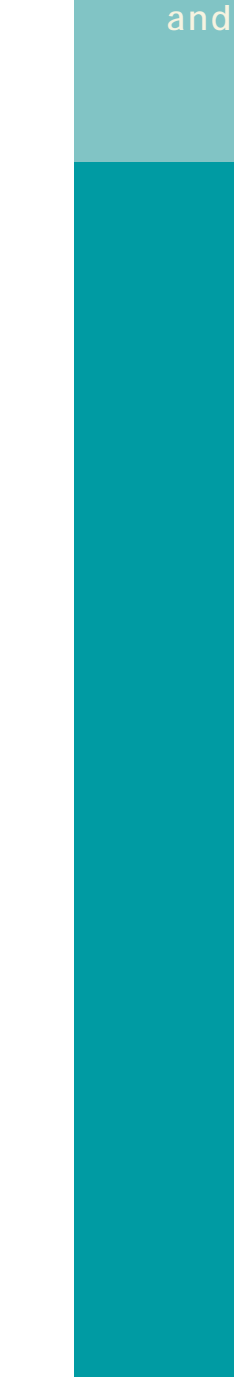

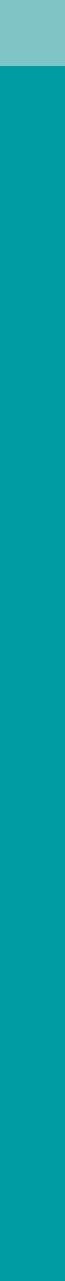

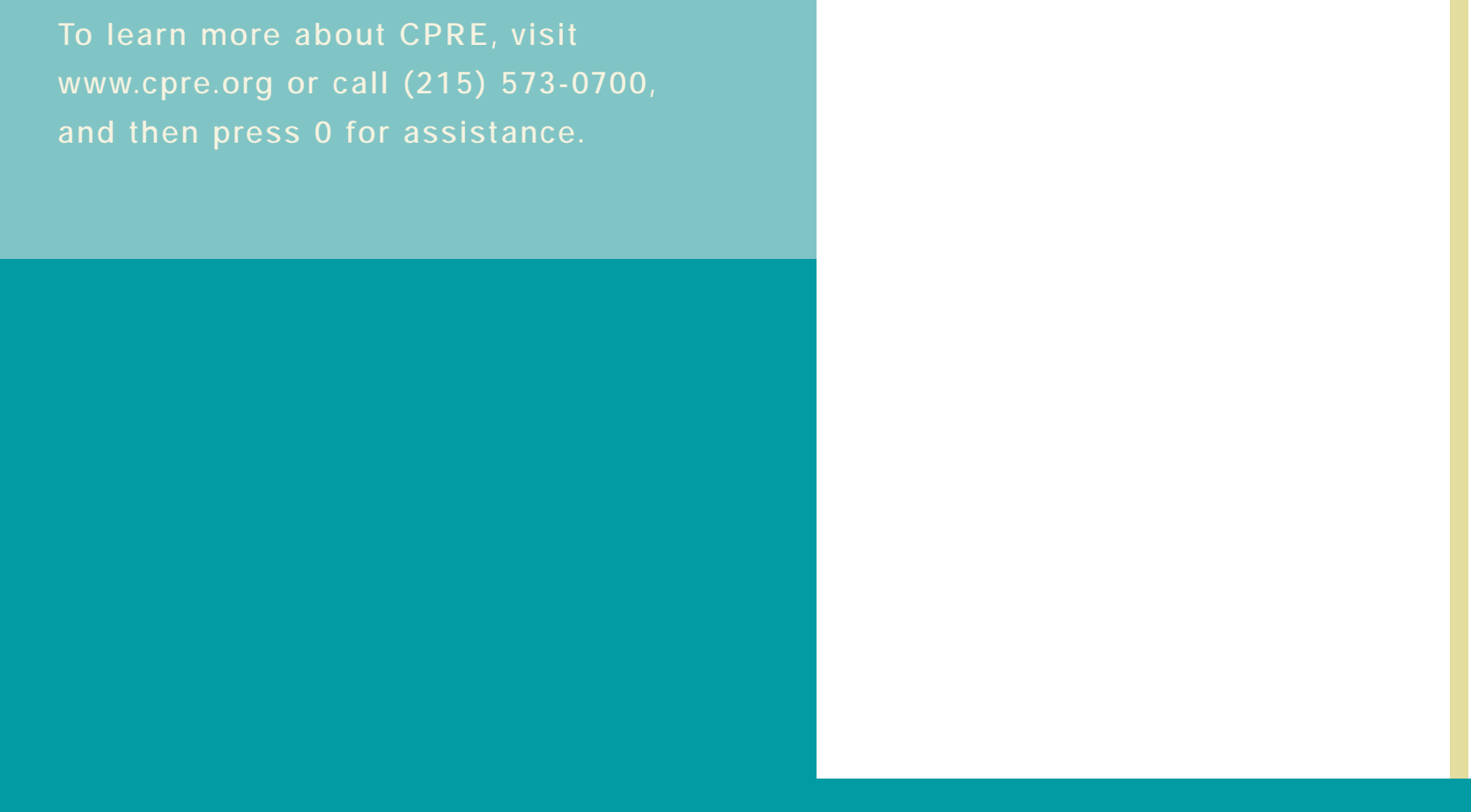

The Univimination Statement

The University of Pennsylvania values diversity and seeks talented students, faculty, and staff from diverse backgrounds. The University of Pennsylvania does not discriminate on the basis of race, sex, sexual orientation, religion, color, national or ethnic origin, age, disability, or status as a Vietnam Era Veteran or disabled veteran in the administration of educational policies, programs, or activities; admission policies, scholarships, or loan awards; and athletic or University administered programs or employment. Questions or complaints regarding this policy should be directed to Executive Director, Office of Affirmative Action, 133 Blockley Hall, Philadelphia, PA I9104-602I or (2I5) 898-6993 (Voice) or (2I5) 898-7803 (TDD). 


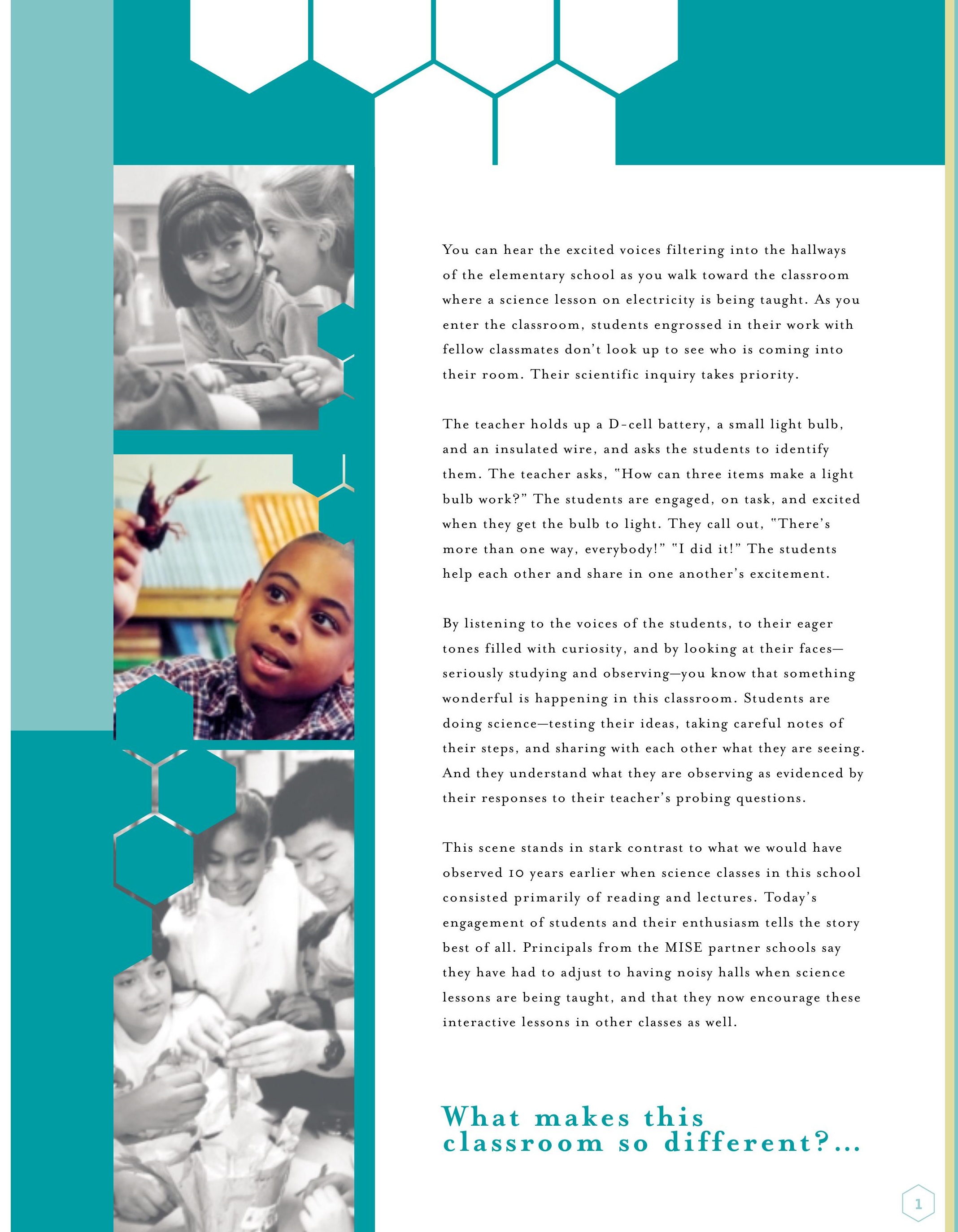


MIS E's theory of action for building district capacity to improve science teaching consisted of the following actions taken in collaboration with the partner districts:

...The district's partnership with the Merck Institute for Science Education (MISE)

MISE began partnering with four school districts-three in New Jersey and one in Pennsylvania-IO years ago. The success that the partners have had in improving instructional practice in science is anchored in the belief that to make lasting improvement in teaching and, consequently in learning, one must work systemically on multiple domains of the district and school culture at the same time.

MISE invited four school districts to come together to build a professional community in science, a community which valued teacher expertise and invested in the continued professional learning for teachers, a community that worked together to improve teaching and learning in science. MISE worked with its partners to create their own professional communities, to build their capacity to support the continuous improvement of teaching, and to align their policies and resources with their shared vision of good practice.

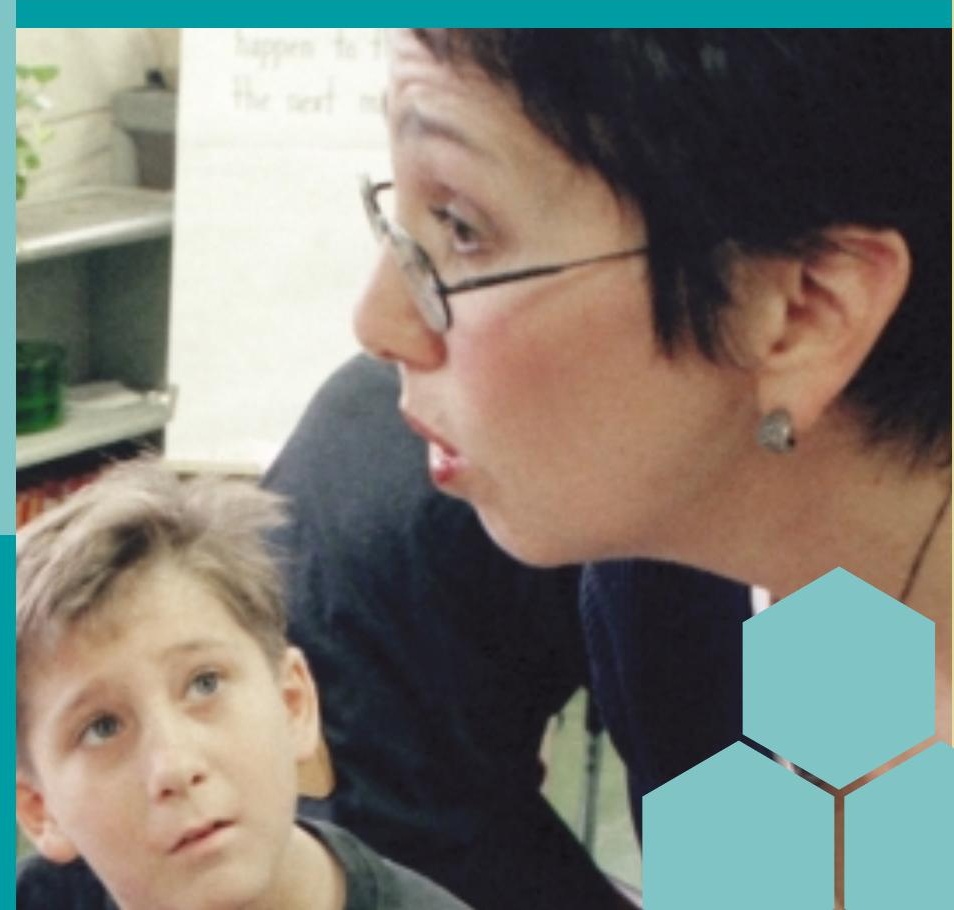

1. Develop a district professional community around science to promote the continuous improvement of science teaching and the development of teacher expertise;

2. Develop a shared vision of reformed practice with district leaders that is grounded in inquiry and consistent with state and national standards;

3. Develop new curriculum frameworks for science that are aligned with state standards and support the adoption of new instructional materials compatible with inquiry-centered instruction;

4. Design and support high-quality professional development for teachers to master the new curriculum and inquiry-centered instruction;

5. Develop instructional leaders at the district and school levels who under. provide on-site support for reformed practice, encourage its spread, and plan and lead professional development;

6. Support the adoption and development of assessments that inform science instruction and help the districts monitor the impact of the reform; and

7. Respond to and influence policymakers at all levels-including district, local community, state, and national-in order to expand the impact of the reform. stand distributed leadership and can

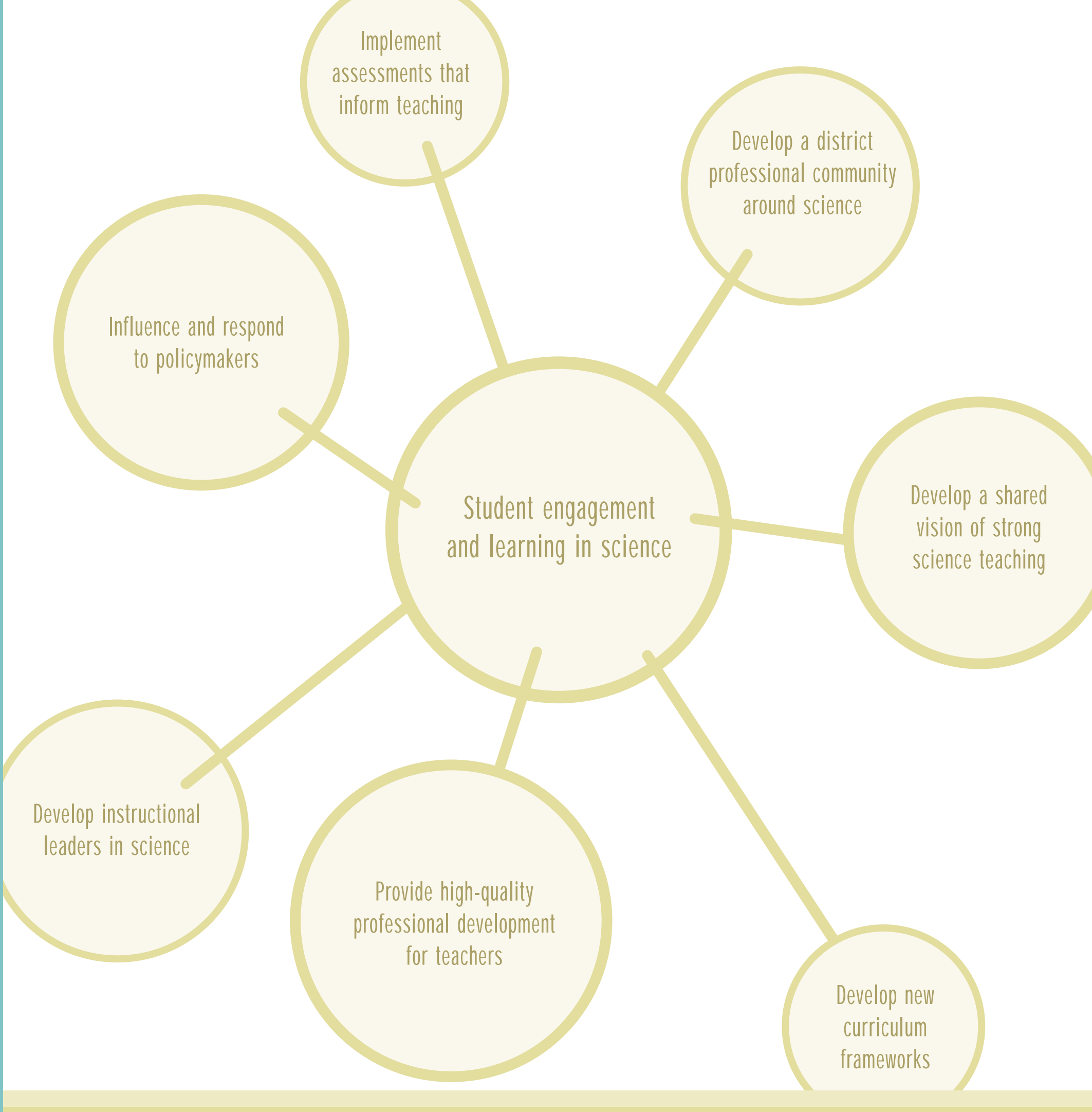

This publication reviews how MISE and its partners have addressed these seven domains of district action in a systemic way and, as a consequence, have altered the norms of classroom practice and created professional communities in science. In addition, it examines how thece forts have affected students who are featured in the center of this publication, as they lie at the heart of this work. Finally, this report shares some thoughts about the attributes that have made this initiative a success. 
School board members and central office leaders became champions of reform who made the work of the partnership with MISE a district priority. With district support, science, sometimes forgotten in the rush to focus on what is on the state assessment, became a focus for improvement. With district support, teachers, fresh from summer institutes and armed with new science resources, were willing to engage students in scientific inquiry. Momentum built. Parents spoke of children newly enthused about science and publicly praised the changes taking place in science education.

One measure of MISE's achievement is its success in building the capacity of the districts to sustain improvement over time. While MISE initially bore a significant portion of the cost of purchasing new curriculum materials and providing professional development for teachers, the partners leveraged other funds to expand their efforts and the districts reallocated their resources to sustain the work. In the last few years, the financial responsibility has shifted back to the districts.

with I4 different superintendents, an indication with ry different superintende However, because MISE staff engaged a broad range of district and school leaders-directors of curriculum and instruction, science supervisors, principals and, most importantly, teachers -the Partnership's work has continued. One powerful mechanism for developing support was MISE's district advisory committee. By insisting that broad-based teams represent each district, treating those teams as serious colleagues, and supporting their learning, MISE built a professional community across the Partnership.

All four districts have:

Increased their expenditures on science instructional materials

- Provided more time for professional
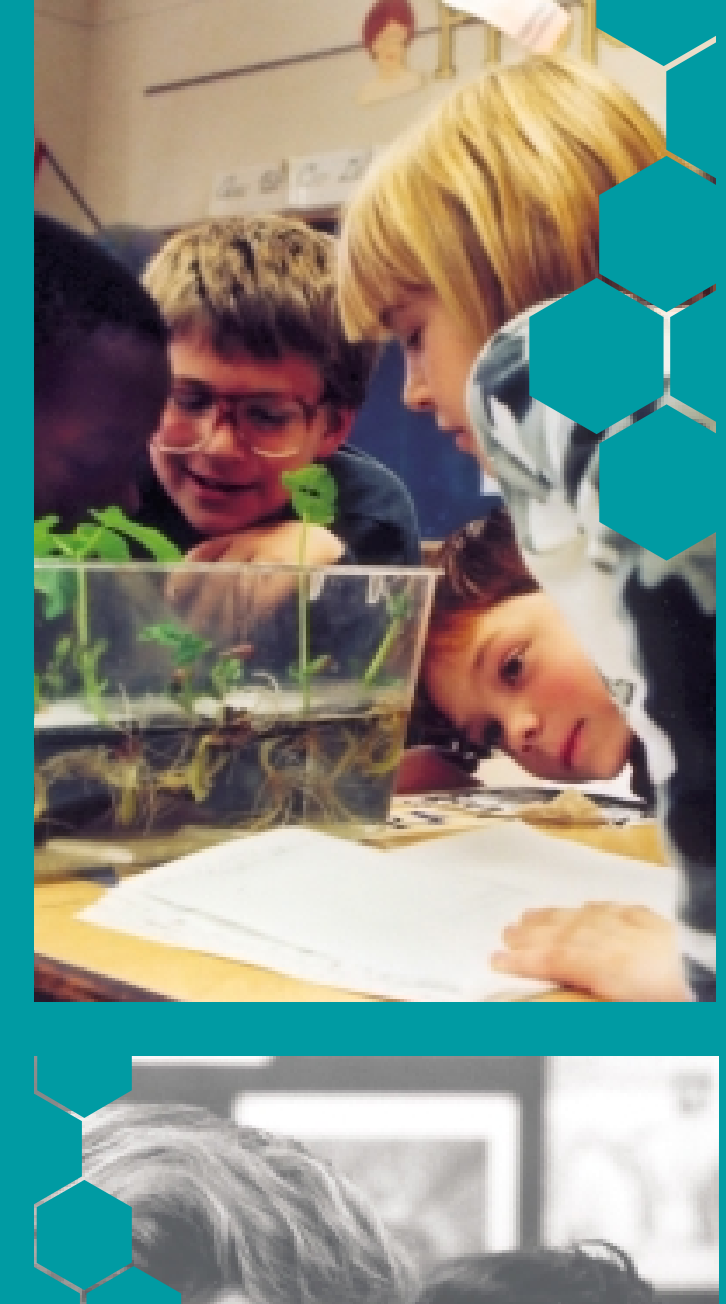

$$
3 . \text { - Superintendent }
$$

\section{Superintendent} development

- Developed the capacity to plan and deliver professional development on their own; and - Used the MISE Peer Teacher Workshops as models for organizing and delivering professional development in all subject areas.
The real staying power from MISE is on the inside. The key partners are teachers who are enlightened, equipped, and motivated."

"...The change in the school has been great and visible and if that's communicated to the Board and the community, why wouldn't they support it? It's like enlightenment: you can't put out the flame."

\section{- Elementary Principal}

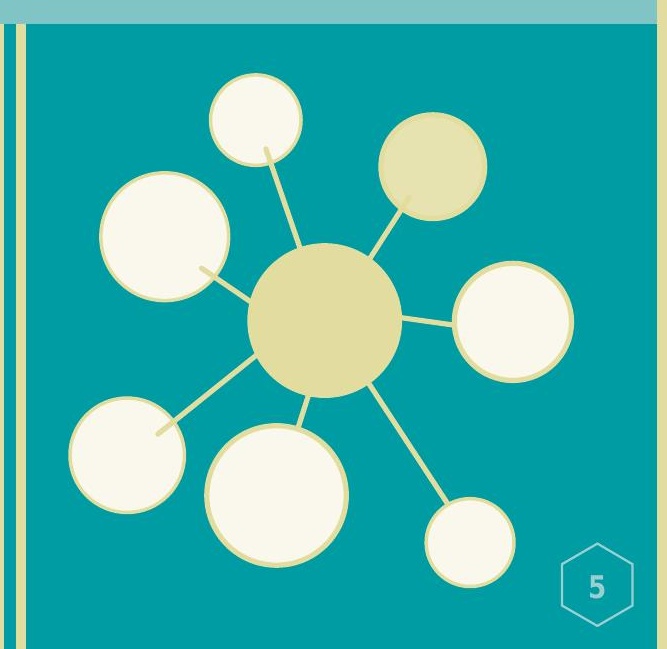


The work of MISE with its partner districts is guided by a vision of science classrooms in which inquiry is an integral and regular part of the learning experience of all students. Inquirycentered teaching and learning imitates the thinking and methods of scientists to help students explore and understand the natural

world. The Institute's approach to instructiona reform rests on the premise that when students are engaged in legitimate inquiry, they develop a greater interest in, and deeper understanding of science than is possible through more conventional instructional approaches.

This view of high-quality science education hold that the most important instructional experience are investigations that challenge students to observe, question, hypothesize, test, and defend their explanations of natural phenomena.

Through these experiences, students develop the skills and habits of mind needed for scientific work. To teach in this manner, teachers must have a firm grasp of the subject matter so they can encourage students to ask critical questions and help them seek meaningful answers, and they must be able to plan and manage active classroom environments that encourage inquiry and support students as they test hypotheses.

Making the shift to inquiry-centered teaching in science requires that the vision of good practice be widely understood and shared and that the new norms of practice be embedded in school and district cultures and policies.
MISE staff recognites that developing inquiry-centered classrooms requires:

- Investment in teacher leaders who can demonstrate inquiry in their classrooms and advocate its use by others:

- Long-term support for teachers who are working to incorporate new teaching strategies into their practices; Policymakers and administrators willing to give science greater priority and invest more in the instructional materials required for successful use of inquiry in the classroom

Administrators to adopt new standards of good practice so hey understand what they are observing

Outreach to parents so they understand what their children are experiencing and why.

MISE staff recognizes that these are essential elements of a systemic approach to the reform of science education, along with investment in teacher leaders who can demonstrate inquiry in their classrooms and advocate its use by others and administrators who understand

“I don't think of MIS E as an initiative anymore. It's not special in my mind anymore. It's not the new kid on the block and that's a good thing. It's part of our culture now. It's in the culture of the district now."

- Elementary Principal 
Standards-based classrooms where students engage in science investigations require materials

and resources one wouldn't necessarily fin

elementary classrooms. This was especially true in the early I990s when MISE began its school district partnerships. Then district curriculum guidelines for science were vague, seldom followed, and often ignored and district instructional expenditures for science were low. This was the reality that MISE set out to change.

MISE opened resource centers in New Jersey and Pennsylvania stocked with instructional materials, children's books, periodicals, and videotapes that focused on the teaching and learning of science and gave teachers access to standards-based instructional materials that could expand their teaching repertoire. Teachers eagerly responded. District teachers and administrators began previewing materials before selecting new curricula and MISE staff assisted by advising on materials that might best meet their needs.

MISE also broadened teacher horizons by facilitating district team visits to classrooms wher challenging, reform-based science instruction was taking place. Teachers were encouraged to attend national conferences. Together, these experiences laid the groundwork for districts to create curriculum frameworks for science instruction and to select science instructional materials to support those frameworks.
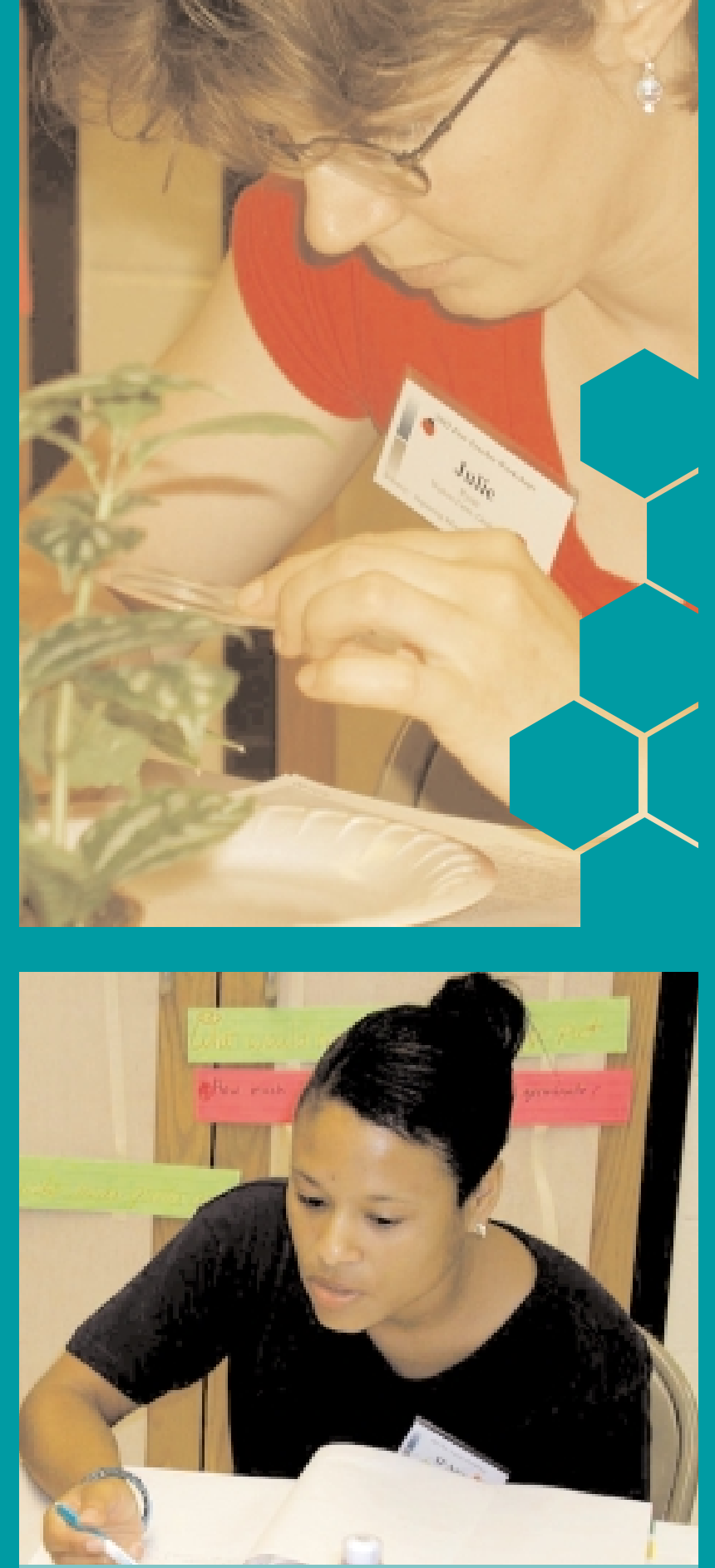

Involvement with MISE is the major influence in where we are now. It helps provide resources and training and the tools necessary to move forward." - Teacher
With support from MISE staff members, the districts have - Greated frameworks in science for kindergarten through eighth grade;

- Selected and implemented standards-based curriculum modules;

- Developed their own resource centers for the storage, distribution, and refurbishment of science materials; and

- Assured students of exposure to a well-balanced science curriculum.

In short, well-structured frameworks incorporating standards-based science modules focused on important concepts have replaced the once fragmented and uncertain science curriculum.
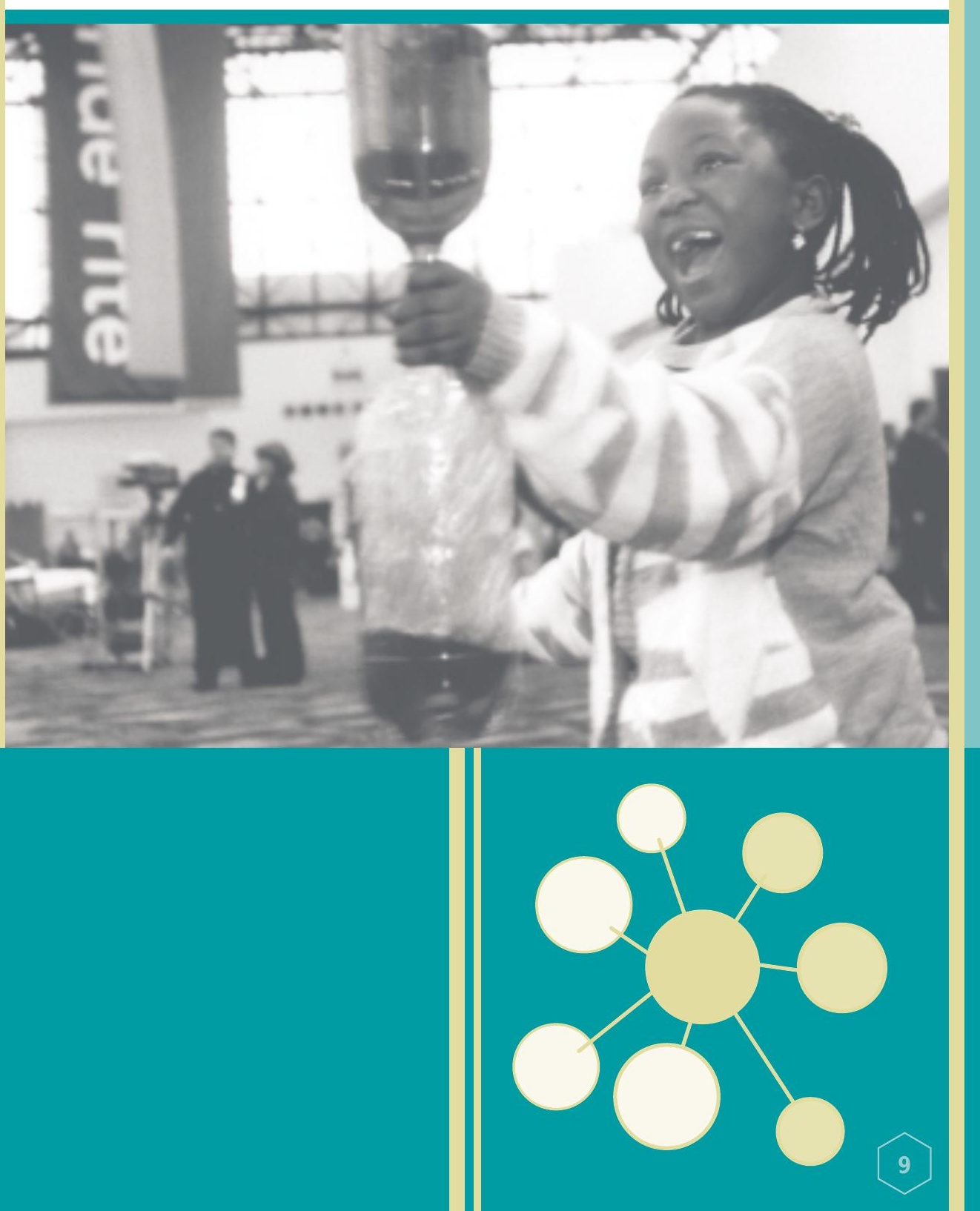
Perhaps the central proposition of the MISE theory of action is that participation in

high-quality, curriculum-based professional

development will lead to significant changes in

teaching practice, which in turn will lead to

improved student performance.

MISE's professional development programs initially focused on building local capacity by creating teams of teachers to lead science reform in their own schools and districts. The Leader Teacher Institute was a three-year program designed to deepen teachers' science knowledge and skills,

strengthen their teaching practice, develop their leadership skills, and at the same time develop a common vision of what a standards-based science classroom should look like. And while this

experience was widely praised by participants and district administrators, CPRE researchers found it had profound effects on the classroom practice of the participating teachers; all agreed that to spread the new teaching strategies more teachers needed to have access to MISE professional development programs.

In response, MISE and its partner districts with created Peer Teacher Workshops. These one-week professional development opportunities focus on teams of teachers come together for four days in the summer and two follow-up sessions during the school year in order to deepen their knowledge of science content, strengthen their teaching skills, and build a community of shared practice. Peer Teacher Workshops are led by instructional teams consisting of accomplished teachers, MISE staff, and educators with content expertise relevant to the science curriculum module being studied. Over 150 workshops have been offered and over 3,000 teachers have participated. support from the National Science Foundation specific science curriculum modules. Grade-level
"The teachers have all become critical consumers. Before it was almost expected that professional development would be boring. You now know what good, highquality professional development looks like. You participate, you're an active participant"

District Administrator

Peer Teacher Workshop Participation, 1996-2002

\begin{tabular}{|c|c|c|}
\hline Year & $\begin{array}{c}\text { Number } \\
\text { of PTWs }\end{array}$ & Enrollment \\
\hline S ummer 1996 & 6 & 169 \\
\hline S ummer 1997 & 8 & 195 \\
\hline S ummer 1998 & 22 & 506 \\
\hline S ummer 1999 & 36 & 525 \\
\hline S ummer 2000 & 32 & 667 \\
\hline S ummer 2001 & 37 & 536 \\
\hline S ummer 2002 & 25 & 577 \\
\hline Total & 166 & 3,175 \\
\hline
\end{tabular}

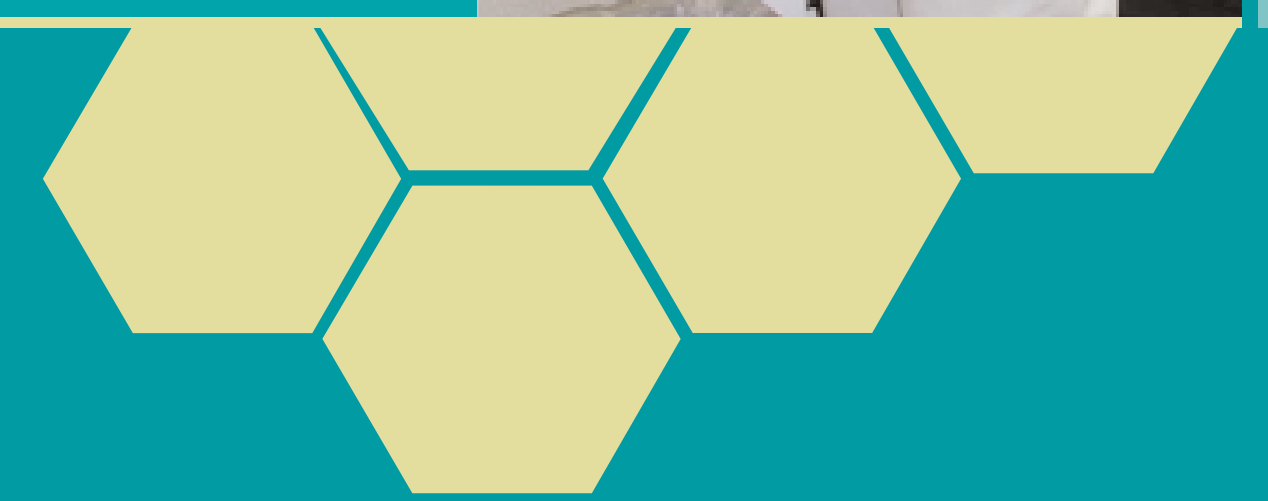

MISE believes that good professional development programs should: - Be based on a clear vision of good practice;

Be linked to specific curriculum units and focused on the content teachers must teach;

- Be carefully designed and planned to provide experiences that will transfer to the classrooms of the participants; - Model good instructional practice:

- Be intensive but also extended over time to allow for practice and reflection;

Provide follow-up support in the classroom; and

- Be led by accomplished teachers.

This approach to professional development engaged teachers as evidenced by their continued participation and their changed practice. CPRE researchers documented the dramatic shift in classroom practice in the MISE Partnership schools. Inquiry-centered instruction has become the norm in most of the schools. Focusing on higher-order thinking skills, using questions that provoke thought and inquiry, encouraging substantive conversation, and allowing time for reflection and interpretation of meaning are all aspects of high-quality instruction. Overall, science teachers who had participated in MISE professional development showed greater evidence of these qualities in their teaching as observed by CPRE researchers than those without MISE professional development.

Within the districts, there is broad acceptance of the principles that guide MISE's professional development programs as evidenced by their use in partner districts to support curriculum revisions in other areas such as literacy, mathematics, and social studies. 
In Ms. Tyrone's fourth-grade class, students are studying ecosystems-terrariums assembled by the students by joining 2 two-liter soda bottles. As students enter the room, they are immediately drawn to their terrariums. As they bring them to their desks for observation, the teacher begins to ask questions:

Ms. Tyrone:

know you're excited because there have been changes in your eco-towers. What do you observe?

Student 1:

Student 3: My cricket is missing! I can't see the isopods.

Student 4: The water was yellow and now it's not.

Ms. Tyrone: So the water has clarified.

(She writes this new word on the board.)

Why do you think that happened?

Student 1: Maybe the algae?

Student 2: Do snails have teeth?

Ms. Tyrone: What do you think?

Student 2: I don't know. I think I see a suction cup.

Ms. Tyrone: Let's take a closer look with a magnifying glass and draw a picture. What do you think the suction cup is for?

In just a few minutes, the teacher has skillfully laid the groundwork for further investigations in this inquiry-based classroom. Students keep journals for making predictions, recording data, writing down questions, and drawing conclusions. The teacher periodically collects these and makes comments or poses questions.

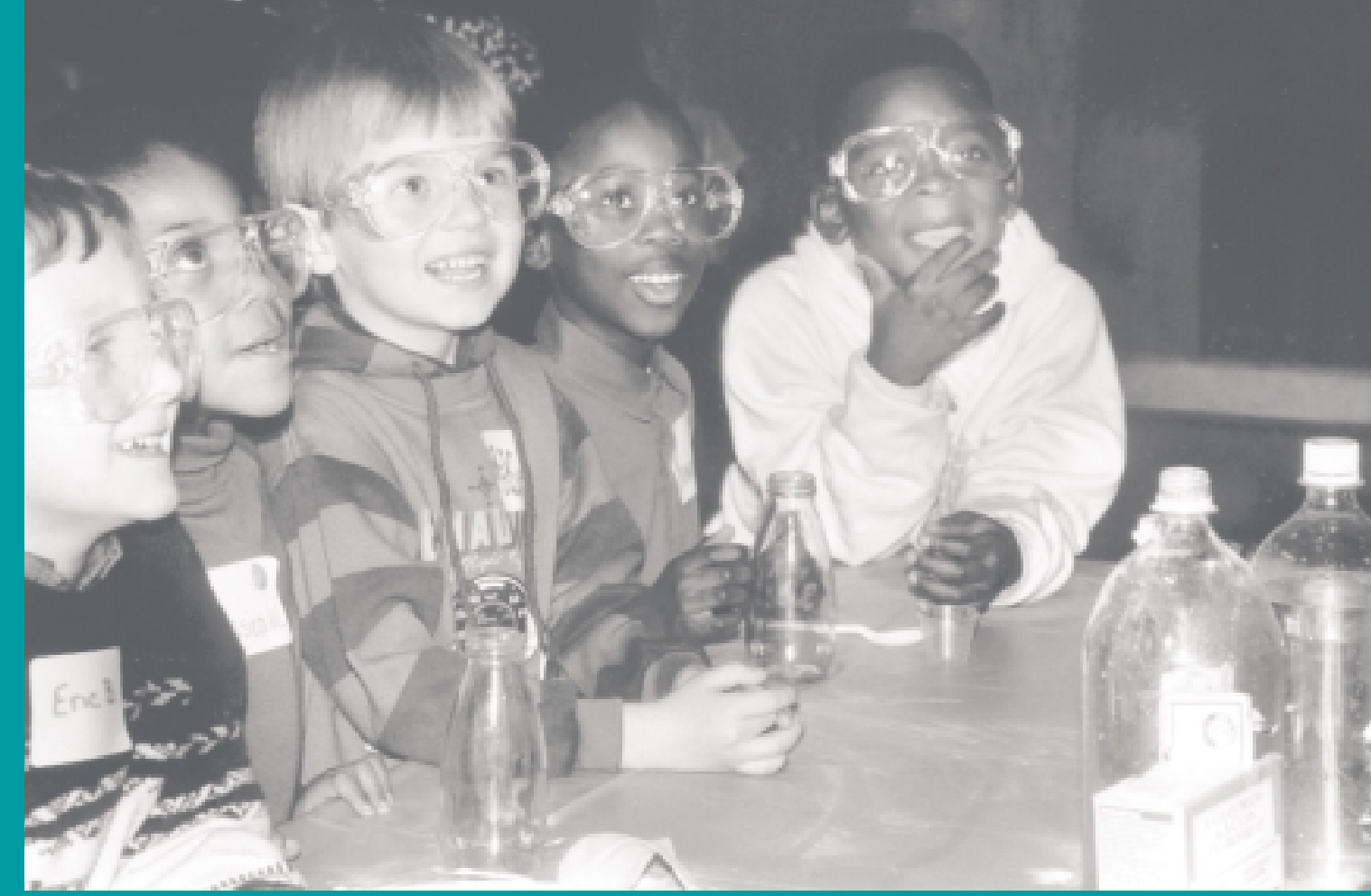

"They love science; it is one of their favorite times of the day."

- Teacher

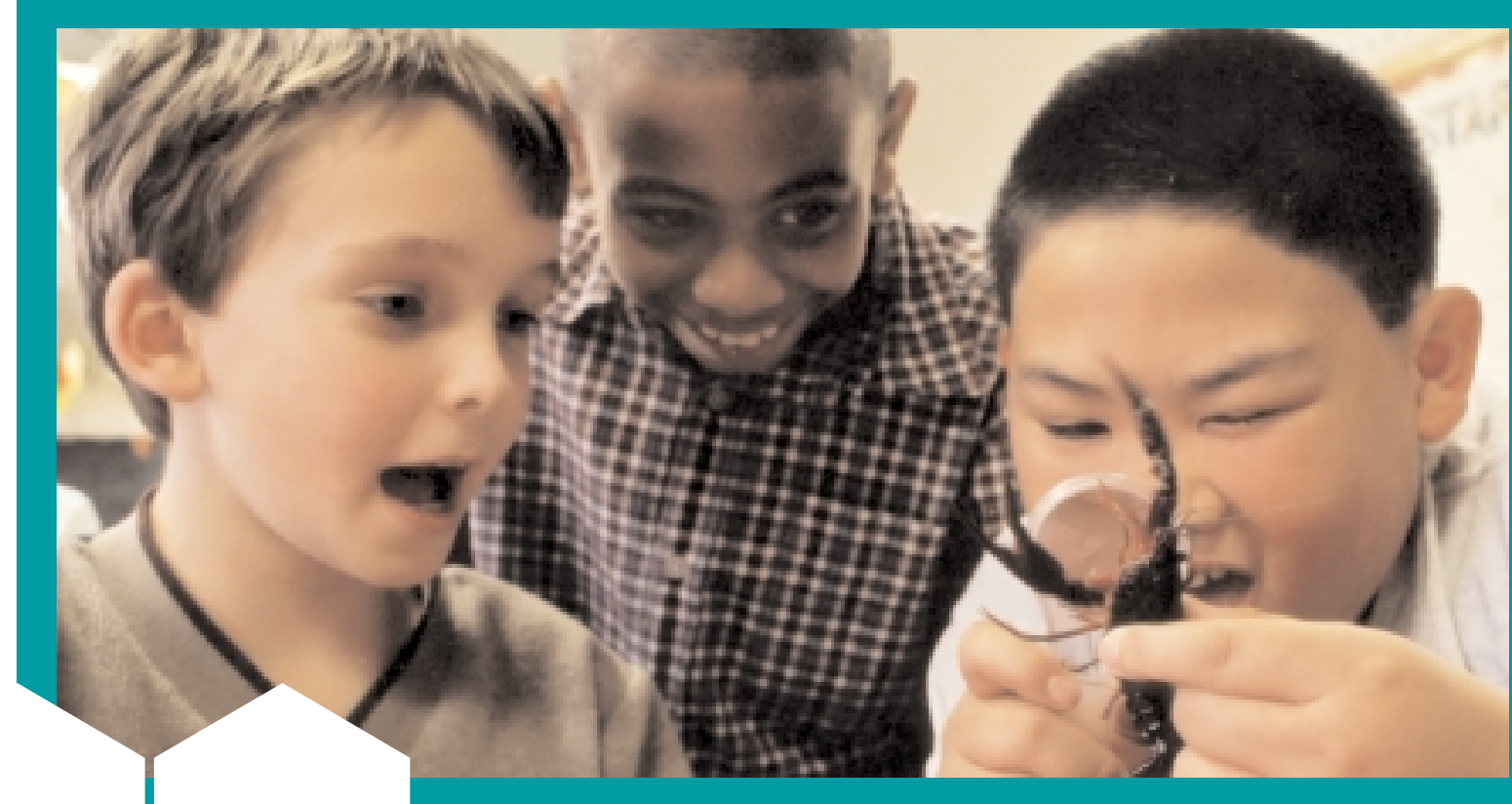

"S tudent interest has increased ten-fold and as a result students are getting more content and better pedagogy."

- Second-grade Teacher

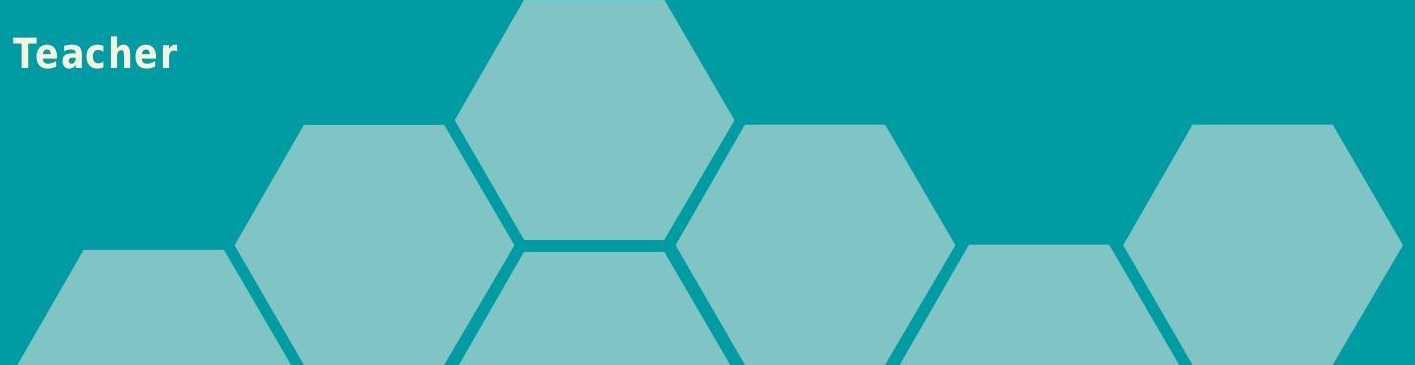


In study after study, researchers confirm that the engagement of school principals and teacher leaders is essential to successfully implementing any instructional reform, and the kind of leadership principals provide is especially importan as it needs to be more than conventional school management. Principals need to be focused on instruction, and they need to develop and use the expertise of teachers who understand the content and how to teach it. MISE leaders believe that principals who are effective instructional leaders.

- Provide vision and focus

- Greate coherence within their schools,

- Support the efforts of effective teachers to help others improve their teaching;

- Support the efforts of teachers to improve their practice;

Build strong professional communities that focus on results;

Promote collaboration

- Provide assistance to teachers who need it,

- Allocate resources, including time, to support school instructional priorities; and

Buffer their staffs from countless distractions.
'The June Principals' Institute was inspiring, helpful, motivational, useful, current, researchbased; a great experience.

The information was relevant to science and other disciplines."

- Principal

MISE leaders also understand that transformation of practice requires teacher leaders who.

Can demonstrate good practice in

their classrooms;

Are willing to make their own practice public

Can gain the respect of their peers and bring them together in collective work;

Are willing to go into other classrooms and provide constructive feedback; and

Can plan and lead professional development.
In order to foster the development of teacher leadership, MISE developed the Leader Teacher Institute and gave accomplished teachers leadership roles in the Peer Teacher Workshops. To support principals, MISE tailored professional development opportunities. to address their role wi instructional leaders. Together, MISE suff and a group of principals from the partner districts designed a Principals' Institute to:

Build consensus on the shared vision for standards-based science instruction by providing opportunities for principals to view videotapes of practicing teachers and discuss what they have seen and how it relates to standards-based instruction;

- Offer strategies to encourage the development of professional school communities that focus on results and promote collaboration and continuous improvement

-Show principals what distributed leadership looks like in practice; and - Provide networking opportunities so principals can share concerns and successes, and develop professional connections to assist them in the future.

These efforts have strengthened collaboration in the schools, and increased the capacity in the schools and central offices to support instructional improvement. CPRE researchers found that over time teachers became more comfortable seeking assistance from their colleagues and roported that the assistance was more useful than the feedback they had received in the past. 
The commitment of MISE and its partner school districts to improving student performance in science is evidenced not only in their investments in professional development, but by their efforts to measure student performance in science.

However, they have found that the readily available and affordable measures seem insensitive to the kinds of changes that are occurring in students classroom experiences (and, by inference, learning). Furthermore, it has proven challenging to develop measures aligned with the shared vision of teaching and learning in science that are technically sound, administratively feasible, and affordable.

Despite these challenges or perhaps as a result of them, MISE and its partner districts have developed an ambitious assessment plan that is now being implemented.

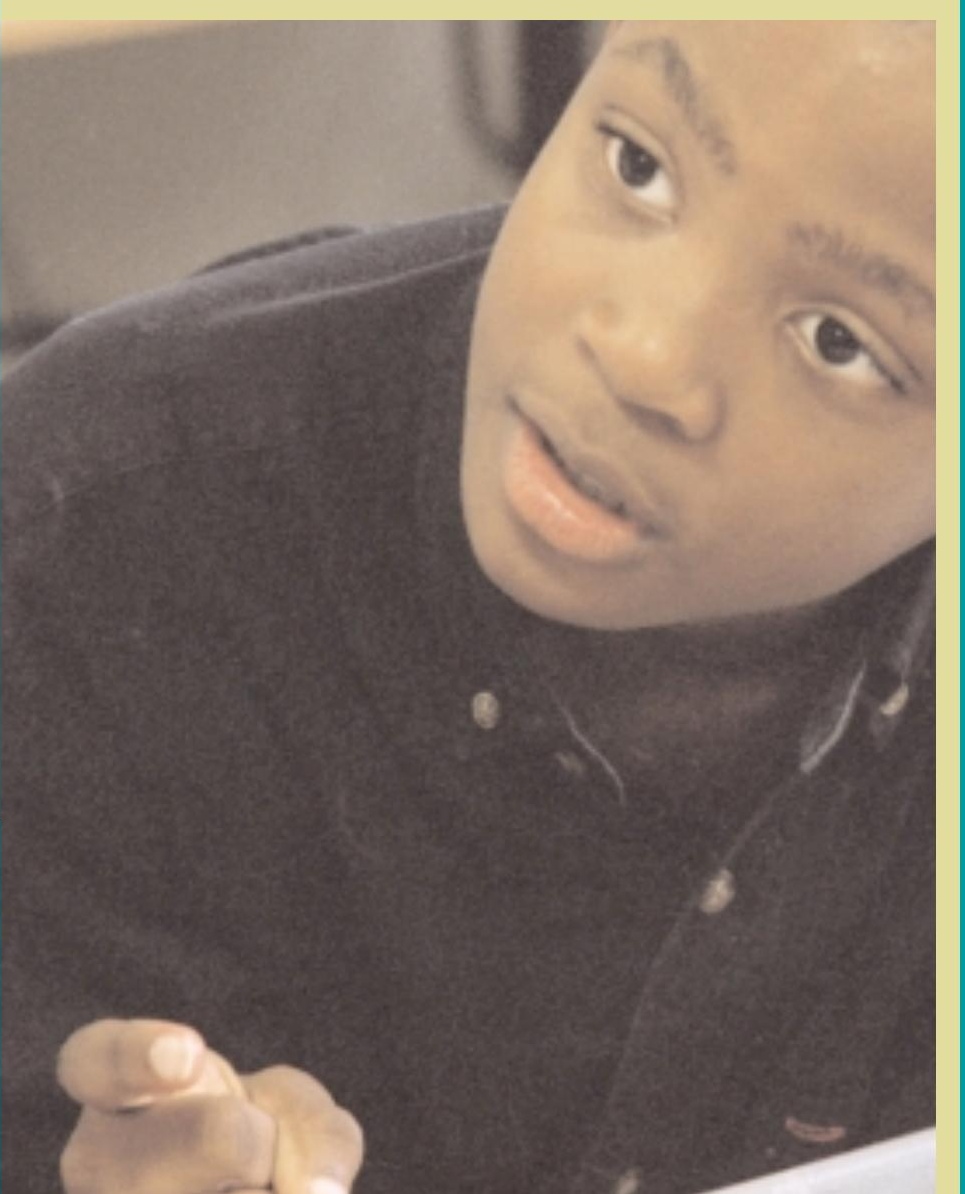

Designed to address the needs of classroom teachers and local decision-makers, the assessment plan includes the use of:

- A nationally recognized, standardized test consisting of multiple-choice and/or open-ended items focusing on central themes in science. This requirement may be met by the creation of new statewide assessments in science.

- A set of performance tasks tied to the districts' curricula that could be administered district-wide or even across districts in specific grades. For the past three years, the partner districts have worked with MISE to administer selected performance tasks from TIMSS (the Third International Mathematics and Science Study) in multiple grades.

A team of teachers from each of the districts helped to pilot, score, and subsequently modify these performance tasks prior to their second administration and then designed sessions for their colleagues that focused on how to use the information to inform instruction.

- Pre-/post- or summative tasks specific to each science module that could be administered district-wide. District teams have drafted and piloted tasks in many grade levels for science modules being used and are continuously examining student work and revising these tasks.

- Informal, formative assessment strategies for classroom use. As part of the Leader Teacher Institute, teachers examined their assessment practices with researchers from the Educational Testing Service and created grade-level binders containing more than Ioo assessment tasks for teachers to use in their classrooms.
"I have seen the development of teacher understanding. I have seen teachers who used to rely on paper-and-pencil tests and quizzes develop a broader view of how to identify student learning. For me it has meant growth, a change in understanding, a movement from theory to practice."

- Science Specialist

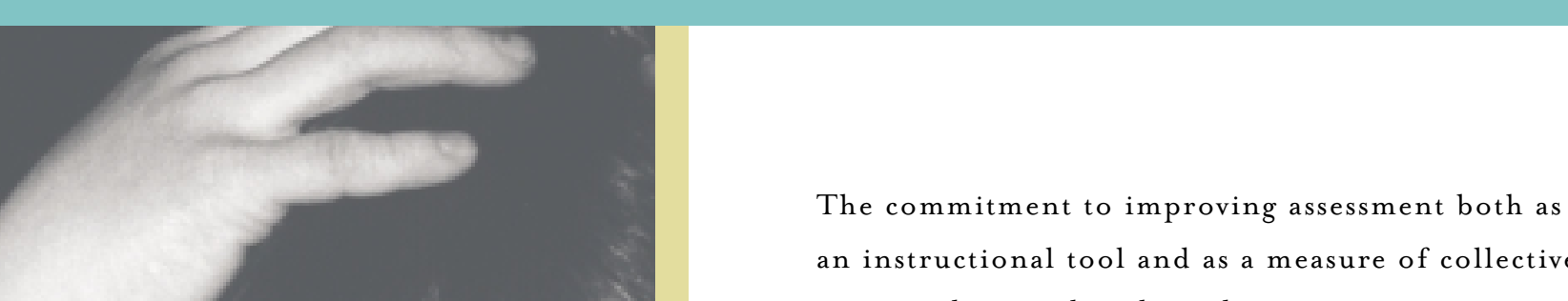
progress has produced results.

While this work is developing the tools needed to assess the impact of MISE's work, the fact remains that the existing standardized tests have not recorded significant district-wide gains in science performance. However, targeted studies by CPRE have found that students whose teachers have been active participants in MISE professional development perform better on these tests than their peers whose teachers have not participated as much. Administrators, teachers, and MISE and CPRE staff agree that student work and student interest in, and understanding of, science have improved. Documenting these changes will likely continue to challenge MISE and its partner districts to come up with even better methods of assessment.

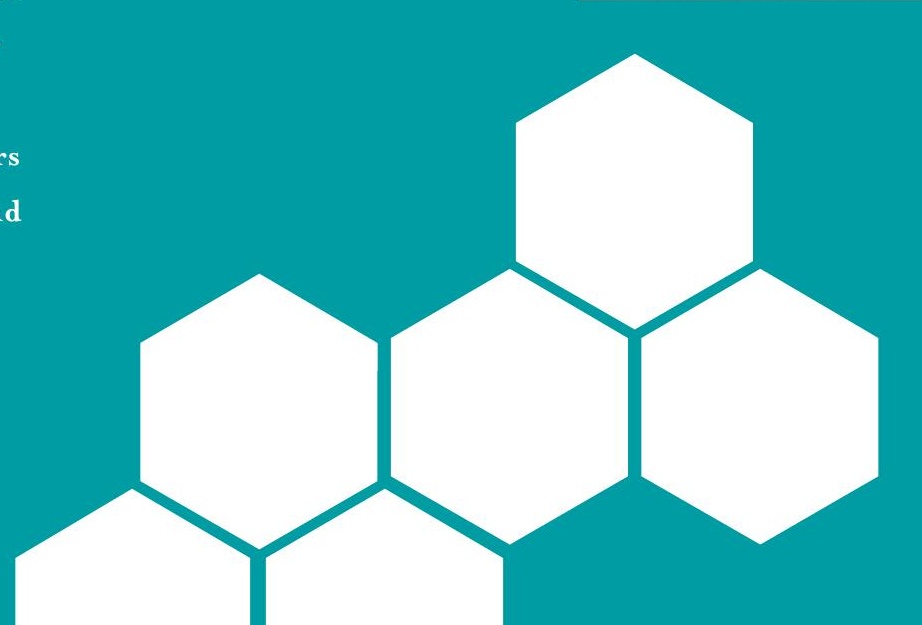

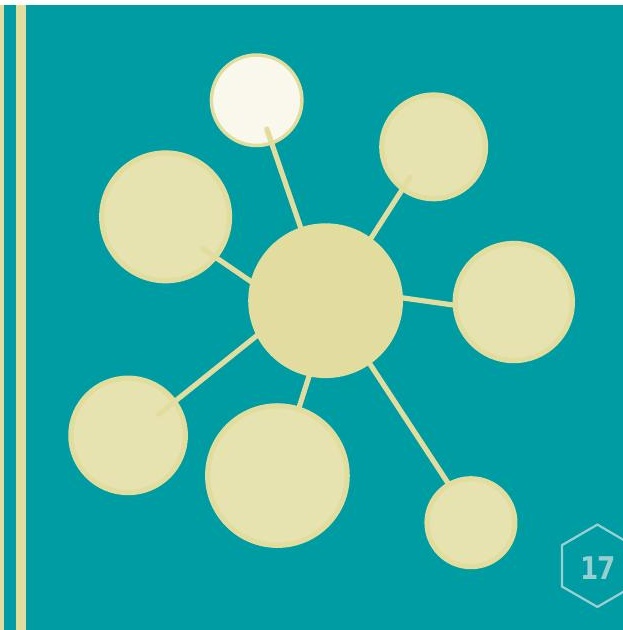


MISE leaders understand that to have a wider, deeper, and more lasting impact on science teaching,

they need to challenge the way policymakers value

and understand science education.

\section{At the local level:}

Superintendents report that changes in district policies have resulted from the MISE Partnership and include:

Adoption of new science curriculum frameworks

Increased support for strong professional development;

Improvements in hiring and recruitment practices that put more emphasis on teachers knowledge about content and inquiry-based instruction,

Increased expenditures for instructional materials

Changes in teacher observation practices; and

Development of new district-wide science assessments.

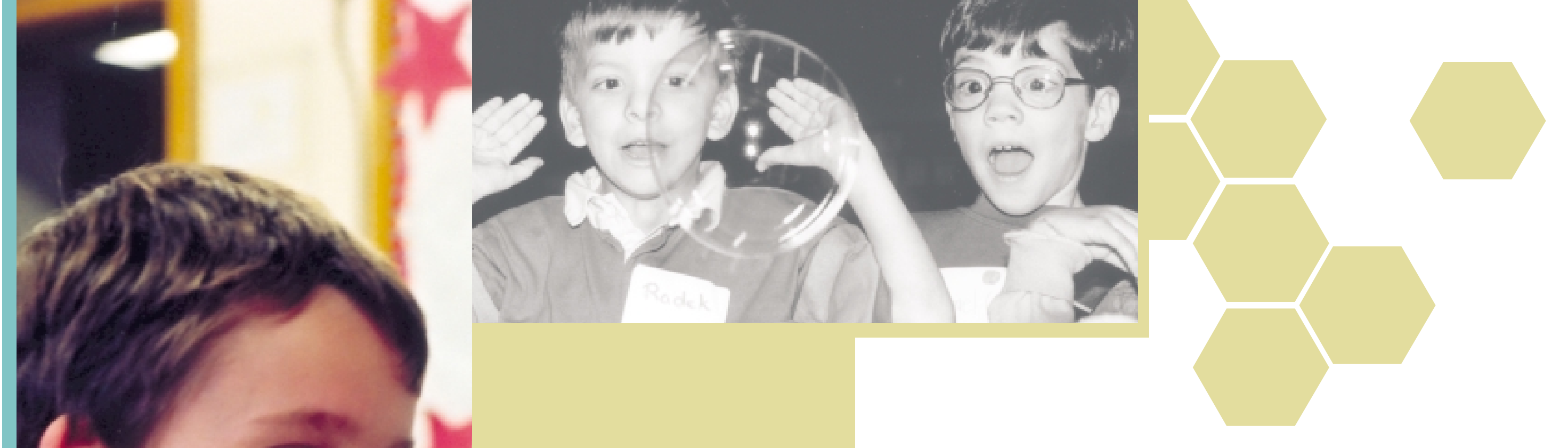

CPRE researchers also found a change in how local leaders think in general about curriculum, instruction, assessment, and professional development because of their involvement in the MISE Partnership. They more clearly understand how important the alignment of these various components is to bringing lasting improvement to instruction.

\section{At the state and federal level:}

MISE leaders have been active at the state level, in New Jersey where MISE staff serve on the New Jersey Science Curriculum Standards Committee and the state's Professional Teaching Standards Board which is responsible for setting high standards for teachers' professional development.

MISE staff members have also worked with leading educational organizations such as the National Science Resources Center and the Educational Testing Service to help develop inquirycentered curriculum and assessment tools. The new assessmen tools are being widely used in the partner districts and are in

"The Partnership made us much more educated in terms of what our curriculum should be. And it's influenced what we look for in new teachers, and that's influenced beyond science and math." - Assistant Superintendent use across the country.

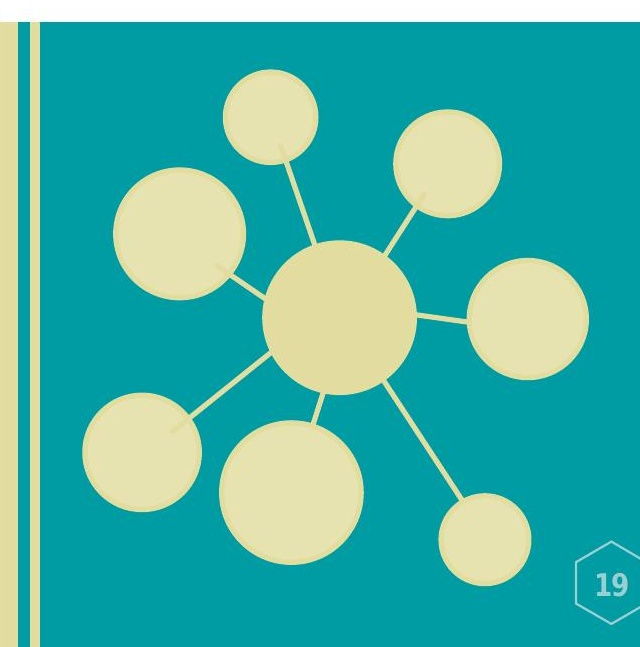


MISE is a learning organization that has responded and adapted to the changing needs of the districts-to the lessons learned along the way. They have leveraged resources, they have kept their focus on improving science instruction, and they have listened to their partners with respect. These and other relatively simple actions reflect what many education reformers today believe are essential steps that need to be followed by those seeking to improve our nation's schools.

When researchers look at districts which have been successful in improving teaching and learning around the nation, they see common attributes that they share. When CPRE researchers looked at the MISE educational reform, they found that many of their actions and decision mirror these attributes-perhaps the clearest indication of why their initiative has proven to be so successful.

Attributes of Successful Districts and Parallel MISE Actions

\section{Standards of performance and practice are defined.}

MISE worked with school and district staff to examine national and state standards, review student work, select new curriculum, and develo performance assessments and their results. MISE articulated a vision of strong science teaching and helped districts to develop curriculum frameworks and revise their teacher observation systems.

\section{Decisions are informed by evidence.}

MISE modeled the use of evidence in selecting curriculum materials and designing professional development, and its district partners have adopted the same approach. MISE also made good use of the results of CPRE's evaluation in its planning

\section{Curriculum is rigorous and effectively implemented.}

MISE connected its district partners with national science education experts and created resource centers to help districts select standardsbased curriculum. MISE helped the districts design systems for supporting the use of the curriculum in every classroom.

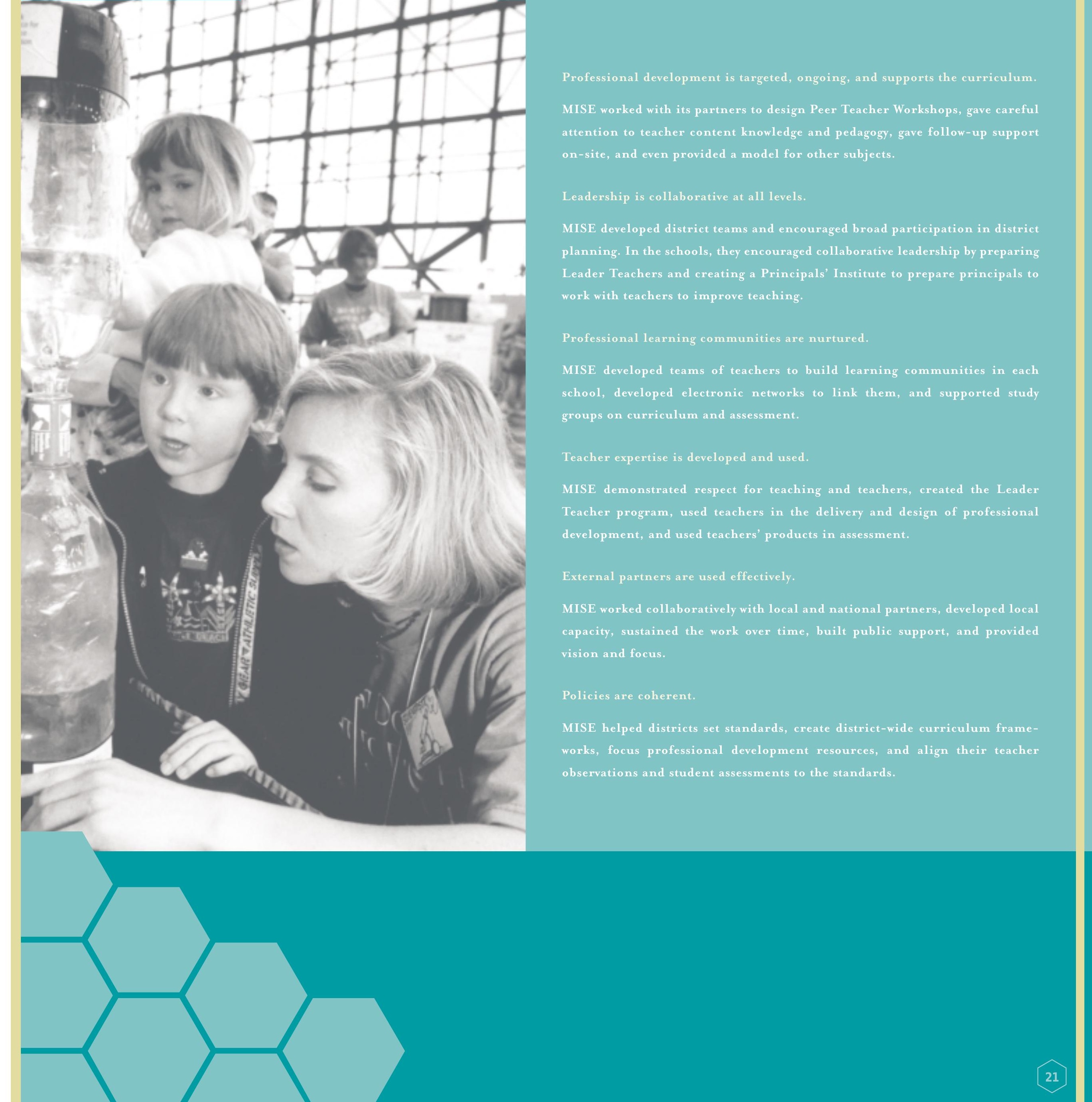


MISE provides a compelling example that other technical assistance organizations might emulate. With its partners, MISE has provided the intense and sustained assistance needed to make significant changes in science teaching. After almost a decade of financial support, sustained professional development, and management guidance, there have been dramatic changes in the fou school districts working with MISE. Central office staff and teachers have become members of professional learning communities that have altered their perceptions of their work. Children have access to better science materials and teachers are more comfortable using inquiry methods to teach science. The partner districts are continuing to improve classroom practice by sustaining the professional development that they designed with MISE and using the evidence available to the from new assessment strategies to identify areas needing attention. The success of MIS and the Partnership demonstrates that serious and sustained efforts to help teachers improve their practice are worthwhile. There are positive results for teachers, for students, and for the participating school districts.

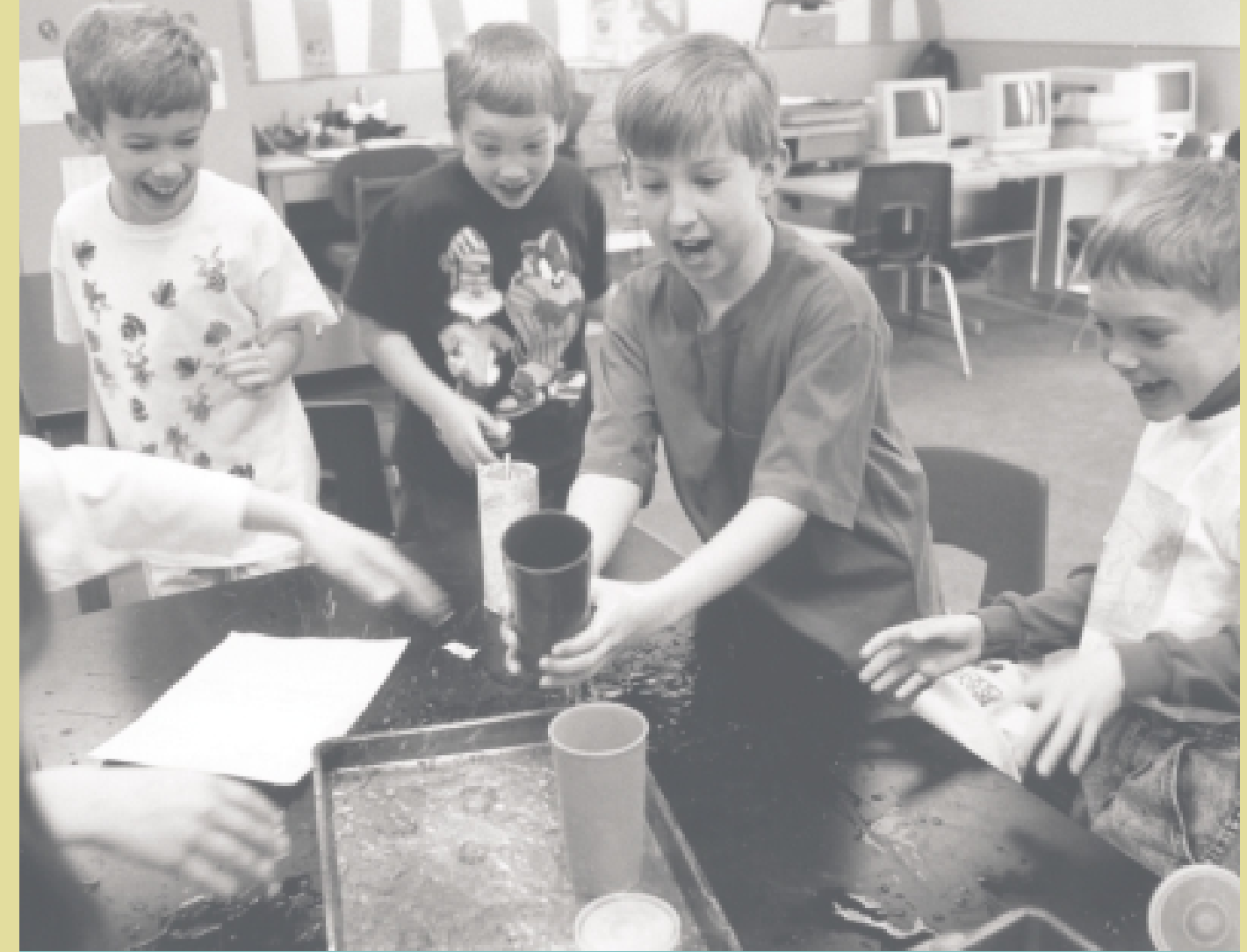

CPRE's Evaluation of MISE

The Consortium for Policy Research in Education (CPRE), located at the Universit of Pennsylvania, was contracted by the Merck Institute in 1993 to document the implementation of the initiative in the four partner school districts and assess its impact on the districts, and on schools, classrooms, and students. Between 1993 and 2002, CPRE hegularly interviewed school and distric staff, observed science classrooms, surveyed teachers, developed case studies of schools, examined student achievement data, and conducted special analyses to answer questions of concern to MISE and the districts. The long-term character of this research and the breadth of the data set provide a unique look at the development and impact of a technical assistance organization. This work is reported in eight annual reports published between 1994 and 2002 . These reports are available from CPRE.

\section{cknowledgments}

This overview is based on IO years of work by a large team of people from the Consortium for Policy Research in Education (CPRE) and numerous consultants and associates working collaboratively with CPRE for the duration of the MISE evaluation.

CPRE would like to thank all those who have contributed their knowledge and expertise over the years including: Deanna Burney, Jane Century (consultant), Sister Marie Cooper, Tom Corcoran, H. Dick Corbett, Ada Beth Cutler, Bill Firestone, Peg Hoppe, Seong-Jung Joo, Patty Kannapel, Nancy Lawrence, William Letts IV, Lynn Mcfarlane, Siobhan McVay, Pat Michaels, Linda Morris, Mark Nicolich, Claire Passantino, Patricia Patrizi, Kate Riordan, Kathryn Scantlebury, Alex Schuh, Joan Carroll Stevens, Jonathan Supovitz, Bruce Wilson, Anne Marie Yodlowsky, Susan Goerlich Zief.

We are also grateful to the CPRE communications and administrative staff who supported the publications process throughout the evaluation including: Deborah Schwartz Alexander, Gail Danckert, Marlies Dunson, Christine Gazzara, Robb Sewell, Doris Showers, and Kelly Stanton. We are indebted as well to the late Peg Hoppe whose contributions to this project were immeasurable.

We wish to thank the many teachers, administrators, and students at each of the four school districts selected for the implementation and evaluation of the MISE Initiative: Linden, Rahway, and Readington Township, NJ: and North Penn School District, PA. We truly appreciate their openness and eagerness to share their time and valuable knowledge with CPRE throughout the ten-year evaluation.

Finally, we acknowledge the support, knowledge, and time of the Merck Institute for Science Education, particularly Carlo Parravano, Executive Director and the current and former staff members who have worked on this initiative. 
